\title{
Adenosine A(2A) receptor activation reverses hypoxia-induced rat pulmonary artery smooth muscle cell proliferation via cyclic AMP-mediated inhibition of the SDF1-CXC4 signaling pathway
}

\author{
YANG WANG $^{1 *}$, LEI YING ${ }^{1 *}$, KE-KE JIN $^{1}$, YAN NAN $^{2}$, SUHUA HU $^{1}$, XUEQIN WU ${ }^{1}$, \\ RUYI QI ${ }^{1}, \mathrm{XIN}^{\mathrm{L} U \mathrm{O}^{1}}{ }^{1}$ and LIANGXING WANG ${ }^{3}$
}

\begin{abstract}
${ }^{1}$ Department of Pathophysiology, Wenzhou Medical University, Wenzhou, Zhejiang 325000; ${ }^{2}$ Department of Neonatology, The Second Affiliated Hospital and Yuying Children's Hospital, Wenzhou Medical University, Wenzhou, Zhejiang 325027;

${ }^{3}$ Department of Respiratory Medicine, The First Affiliated Hospital, Wenzhou Medical University, Wenzhou, Zhejiang 325000, P.R. China
\end{abstract}

Received October 7, 2017; Accepted March 27, 2018

DOI: $10.3892 / \mathrm{ijmm} .2018 .3626$

\begin{abstract}
The occurrence and the subsequent development of pulmonary arterial hypertension (PAH) involve complicated mechanisms. Of these, the proliferation of pulmonary artery smooth muscle cells (PASMCs) has been indicated to be closely associated with its progression. Therefore, therapeutic methods targeting PASMCs to inhibit proliferation is an effective method for alleviating PAH. The present study was designed to determine the role of the adenosine $\mathrm{A}(2 \mathrm{~A})$ receptor $\left(\mathrm{A}_{2 \mathrm{~A}}\right.$ receptor) in hypoxia-induced rat PASMC (RPASMC) proliferation. Primary RPASMCs were isolated from the pulmonary artery of adult male SD rats, cultured and used for the following experiments. The mRNA level and protein expression of CXCR4 were measured by reverse transcription-quantitative polymerase chain reaction and western blot analysis, respectively. The cell proliferation of RPASMCs was measured using a cell proliferation assay kit. In the present study, it was demonstrated that the proliferation of RPASMCs was partially mediated by activation of the stromal cell-derived factor 1 (SDF1)-CXC chemokine receptor 4 (CXCR4) axis under hypoxic conditions. In addition, SDF1- $\alpha$ alone upregulated the mRNA and protein expression levels of CXCR4, and stimulated the proliferation of RPASMCs. The protein expression of CXCR4 and the cell proliferation were
\end{abstract}

Correspondence to: Professor Liangxing Wang, Department of Respiratory Medicine, The First Affiliated Hospital, Wenzhou Medical University, 268 Xueyuanxi Road, Lucheng, Wenzhou, Zhejiang 325000, P.R. China

E-mail: wzyxywlx@163.com

*Contributed equally

Key words: adenosine $\mathrm{A}(2 \mathrm{~A})$ receptor, hypoxia, pulmonary artery smooth muscle cell proliferation, cyclic adenosine monophosphate, stromal cell-derived factor 1, CXC chemokine receptor 4 markedly inhibited by application of $\mathrm{A}_{2 \mathrm{~A}}$ receptor agonist CGS21680 or cyclic adenosine monophosphate (cAMP) under hypoxic conditions or treatment with SDF1- $\alpha$ and was reversed by the $\mathrm{A}_{2 \mathrm{~A}}$ receptor antagonist $\mathrm{SCH} 58261$ or 8-bromoadenosine-3',5'-cyclic monophosphorothioate. These results demonstrated that the inhibition of SDF1-CXC4 signaling by the activation of $\mathrm{A}_{2 \mathrm{~A}}$ receptor and subsequent increase in the level of cAMP may be a potential method to ameliorate PAH.

\section{Introduction}

Pulmonary arterial hypertension (PAH) is a progressive disease characterized by sustained elevation of pulmonary vascular resistance, leading to right ventricular hypertrophy and heart failure. Despite extensive investigation, the etiology of PAH remains to be fully elucidated, and may involve an imbalance of vascular effectors, associated environmental factors or other conditions, or associated genetic abnormalities. In addition, it has been suggested that the pathogenesis of PAH is closely associated with vasoconstriction, smooth muscle cell and endothelial cell proliferation, thrombosis and collagen deposition (1-5).

Lower plasma adenosine levels were reported in the pulmonary circulation of patients with $\mathrm{PAH}$, compared with those in control subjects, indicating the possible involvement of the deficiency of adenosine signaling in the development of PAH (6). Currently, adenosine has been suggested as a potent pulmonary vasodilator, exerting beneficial effects in the amelioration of PAH (7-10). In addition, experiments involving adenosine $\mathrm{A}(2 \mathrm{~A})$ receptor $\left(\mathrm{A}_{2 \mathrm{~A}}\right.$ receptor)-knockout mice indicated that $A_{2 A}$ receptor deficiency may also be involved in the development of PAH, characterized by increased smooth muscle proliferation and collagen deposition with abnormal sclerosis/stenosis of distal pulmonary arteries, whereas its pharmacological activation partially reversed these pathological changes (11-14).

As the binding of stromal cell-derived factor 1 (SDF1, also known as CXCL12) to its receptor, CXC chemokine 
receptor 4 (CXCR4), is involved in vascular angiogenesis, neointimal hyperplasia and remodeling, activation of the SDF1- CXCR4 axis is a potential candidate involved in the progression and development of PAH $(15,16)$. It has been suggested in several studies that the activation of CXCR4 partially contributes to hypoxia-induced PAH by recruiting bone marrow-derived progenitor cells to the pulmonary vasculature, and inducing the proliferation of smooth muscle cells and muscularization of the pulmonary artery in rats and neonatal mice (17-20). Therefore, inhibition of the SDF1-CXCR4 axis is considered to be an underlying mechanism in the alleviation of PAH.

Furthermore, it has been reported that activation of the $A_{2 A}$ receptor may downregulate the protein expression of CXCR4 through a heterologous desensitization process on $\mathrm{CD}^{+}$ T-cells, indicating that $\mathrm{A}_{2 \mathrm{~A}}$ receptor activation may partially ameliorate PAH through its interaction with the SDF1-CXCR4 axis (21). However, the possible mode of action and associated molecular mechanisms in the inhibition of PAH remain to be fully elucidated. Therefore, the present study aimed to examine the potential role and underlying mechanisms of $\mathrm{A}_{2 \mathrm{~A}}$ receptor activation in regulating the expression of CXCR4 and associated cell proliferation in pulmonary vasculature, and evaluate its therapeutic benefit in the treatment of PAH.

\section{Materials and methods}

Materials. The $\mathrm{A}_{2 \mathrm{~A}}$ receptor agonist CGS21680, $\mathrm{A}_{2 \mathrm{~A}}$ receptor antagonist SCH58261,CXCR4 agonist SDF1- $\alpha$, CXCR4 antagonist AMD3100, 8-bromoadenosine 3',5'-cyclic monophosphate sodium salt (8-Br-cAMP), 8-bromoadenosine-3',5'-cyclic monophosphorothioate (Rp-8-Br-cAMPS), collagenase type I, 4',6-diamidino-2-phenylindole dihydrochloride (DAPI), propidium iodide (PI), TritonX-100, glycine, and paraformaldehyde were obtained from Sigma; EMD Millipore (Billerica, MA, USA). Fetal bovine serum (FBS), penicillin G, streptomycin, Dulbecco's modified Eagle's medium (DMEM, high glucose) and sterile phosphate-buffered saline (PBS) were purchased from Thermo Fisher Scientific, Inc. (Waltham, MA, USA). The rabbit monoclonal antibody against CXCR4 (cat. no. ab124824) and the rabbit polyclonal antibody against a-smooth muscle actin (SMA) (cat. no. ab5694) were purchased from Abcam (Cambridge, UK). The mouse monoclonal antibodies against $\beta$-actin (cat. no. 3700) were purchased from Cell Signaling Technology, Inc. (Danvers, MA, USA). The BCA Protein Assay kit and SuperSignal (R) West Femto Maximum Sensitivity substrate were purchased from Pierce; Thermo Fisher Scientific, Inc. The DyLight ${ }^{\circledR} 488$ Conjugated Goat anti-Mouse IgG (H+L) (cat. no. 35502) was obtained from Thermo Fisher Scientific, Inc. The peroxidase-conjugated goat anti-rabbit (cat. no. 111-035-006) and anti-mouse immunoglobulin G (IgG)s (cat. no. 115-035-003) were obtained from Jackson ImmunoResearch Laboratories, Inc. (West Grove, PA, USA).

Isolation and culture of rat pulmonary artery smooth muscle cells (RPASMCs). Adult male Sprague-Dawley rats (200-250 g body weight) were purchased from Silaike Experimental Animal Technology (Shanghai, China). Following administration with an intraperitoneal injection of $10 \%$ chloral hydrate, the animals were sacrificed by cervical dislocation. The present study was approved by the guidelines of Wenzhou Medical College (Wenzhou, China; ethics approval no. wydw2015-0201) and the National Institutes of Health Standards of Animal Care. The second to third pulmonary artery branches were isolated from the lungs under a microscope in cold sterile PBS. Following removal of the adventitia and endothelium, the arteries were washed with PBS three times, cut into sections $\left(1 \mathrm{~mm}^{2}\right)$ and then incubated with $0.2 \%$ type I collagenase for $15 \mathrm{~min}$ at $37^{\circ} \mathrm{C}$. The cells were then cultured in high glucose DMEM containing 20\% FBS, penicillin (100 U/ml) and streptomycin $(100 \mu \mathrm{g} / \mathrm{ml})$. The purity of isolated the RPASMCs was analyzed by immunofluorescent staining of SMA. The third to sixth passage primary RPASMCs were used for the subsequent experiments.

Western blot analysis. Following serum starvation with DMEM for $24 \mathrm{~h}$, the RPASMCs $\left(5 \times 10^{5} / \mathrm{ml}\right)$ were exposed to hypoxia $\left(3 \% \mathrm{O}_{2}, 5 \% \mathrm{CO}_{2}\right.$ at $\left.37^{\circ} \mathrm{C}\right)$ or were treated with the CXCR4 agonist SDF1- $\alpha(100 \mathrm{ng} / \mathrm{ml})$ for $48 \mathrm{~h}$, with or without the CXCR4 antagonist AMD3100 $(10 \mu \mathrm{M}), \mathrm{A}_{2 \mathrm{~A}}$ receptor agonist CGS21680 $(2 \mu \mathrm{M}), \mathrm{A}_{2 \mathrm{~A}}$ receptor antagonist SCH58261 $(1 \mu \mathrm{M}), 8$-Br-cAMP $(30 \mu \mathrm{M})$ or Rp-8-Br-cAMPS $(30 \mu \mathrm{M})$ at $37^{\circ} \mathrm{C}$. Subsequently, the cells were lysed with ice-cold RIPA lysis buffer supplemented with PMSF for $30 \mathrm{~min}$. The lysate was then centrifuged at the speed of $12,000 \mathrm{x}$ g for $15 \mathrm{~min}$ at $4^{\circ} \mathrm{C}$. The supernatants were collected and the protein concentrations were determined using a Pierce BCA protein assay kit. Equal quantities of soluble protein $(20 \mu \mathrm{g})$ were subjected to SDS-PAGE (5\% stacking gel and $12 \%$ separating gel) and electrotransferred onto a polyvinylidene fluoride membrane. Non-specific binding sites were blocked with TBST buffer containing $10 \%$ milk for $1 \mathrm{~h}$ at room temperature. The membrane was then incubated with antibodies against CXCR4 $(1: 1,000)$ or $\beta$-actin $(1: 1,000)$ overnight at $4^{\circ} \mathrm{C}$, respectively. Following incubation, the blots were incubated with their corresponding secondary antibodies (peroxidase-conjugated goat anti-rabbit secondary antibodies for CXCR4, dilution 1:3,000; and anti-mouse secondary antibodies for $\beta$-actin, dilution 1:3,000) for $1 \mathrm{~h}$ at room temperature and were then developed using the chemiluminescence detection method (SuperSignal West Pico Chemiluminescent substrate; Thermo Fisher Scientific, Inc.). The optical densities of the immunoblots were quantified by densitometry using a Gel Doc 2000 densitometer (Bio-Rad Laboratories, Inc., Hercules, CA, USA) and further normalized to the scanning signals of $\beta$-actin.

Reverse transcription-quantitative polymerase chain reaction $(R T-q P C R)$ analysis. Total RNA was extracted from the RPASMCs with TRIzol reagent (Invitrogen; Thermo Fisher Scientific, Inc.) and further purified using the RNeasy Mini kit (Qiagen, Inc., Valencia, CA, USA). A Two-step M-MLV Platinum SYBR Green qPCR Super Mix-UDG kit (Invitrogen; Thermo Fisher Scientific, Inc.) was used for the following RT-qPCR analysis. The RT-qPCR reaction system $(20 \mu \mathrm{l})$ contained $10 \mu \mathrm{l}$ aceQ ${ }^{\circledR}$ qPCR SYBR ${ }^{\circledR}$ Green Master mix, $0.4 \mu \mathrm{l}$ primer $1(10 \mu \mathrm{M}), 0.4 \mu \mathrm{l}$ primer $2(10 \mu \mathrm{M}), 0.4 \mu \mathrm{l}$ ROX reference dye 1 (both from Vazyme Biotech Co., Ltd., Nanjing, China),

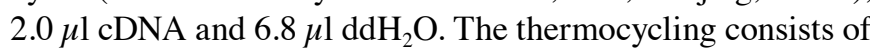
three steps including the initial denaturation $\left(95^{\circ} \mathrm{C}\right.$ for $\left.5 \mathrm{~min}\right)$, 
A

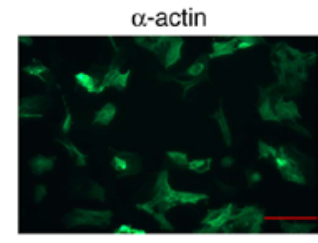

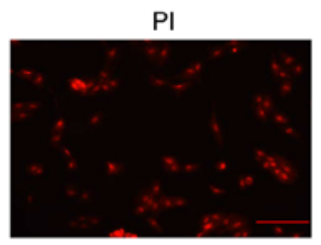
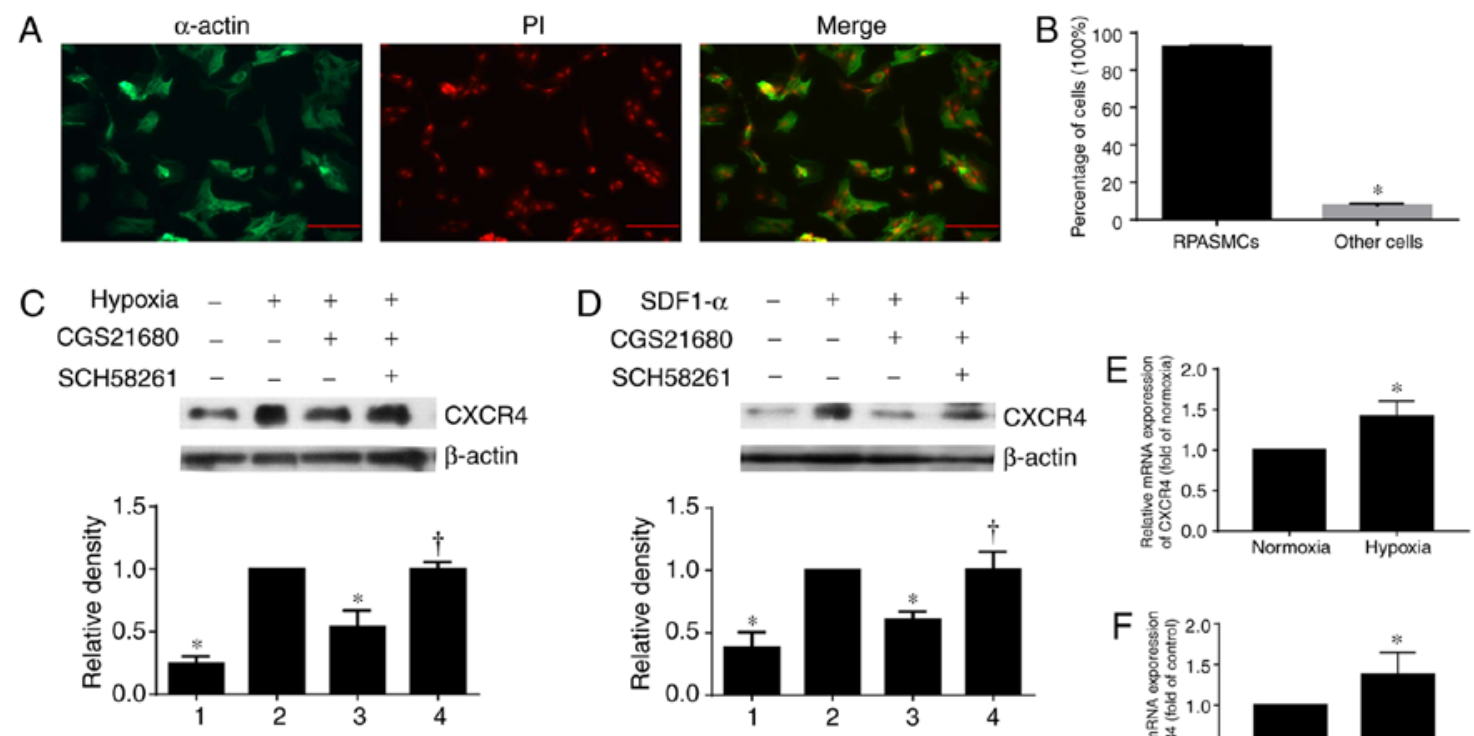

1. Normoxia 2. Hypoxia
3. Hypoxia+CGS 21680
4. Hypoxia+CGS $21680+\mathrm{SCH} 58261$
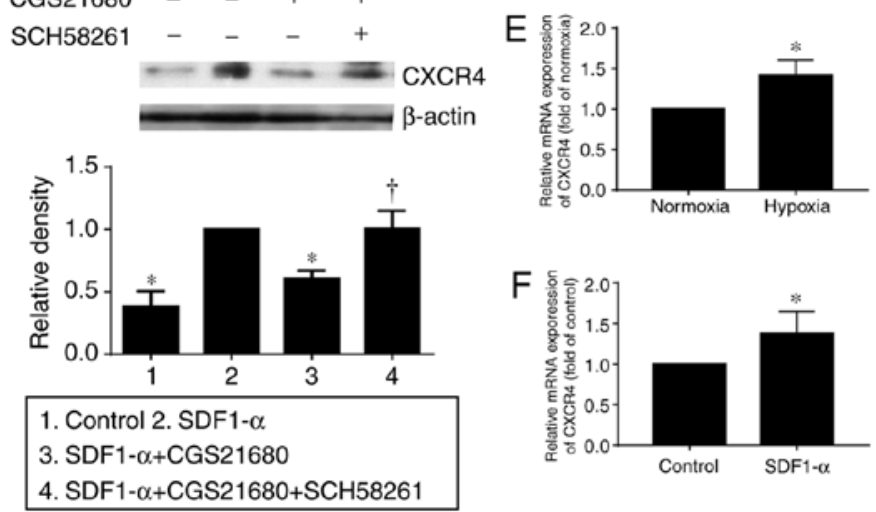

Figure 1. Purity of RPASMCs and expression of CXCR4. (A) Purity of RPASMCs measured with confocal microscopy (scale bar=25 $\mu \mathrm{m}$; magnification, $\mathrm{x} 200$ ) and (B) expressed as the ratio of $\alpha$-actin-positive cells to total cells. Protein expression of CXCR4 under (C) hypoxia or (D) in the presence of SDF1- $\alpha$. The upper panels show western blots of CXCR4, the lower panels show summaries of densitometric quantification of protein expression levels of CXCR4 normalized by $\beta$-actin levels. mRNA expression levels of CXCR4 under (E) hypoxia or (F) in the presence of SDF1- $\alpha$. Hypoxia, $3 \% \mathrm{O}_{2} ; \mathrm{SDF} 1-\alpha, 100 \mathrm{ng} / \mathrm{ml}$; CGS21680, $2 \mu \mathrm{M}$; SCH58261, $1 \mu \mathrm{M}$. Data are presented as the mean \pm standard error of the mean ( $\mathrm{n}=3-6$ for each group). ${ }^{*} \mathrm{P}<0.05$ vs. Control, or RPASMCs treated by hypoxia or SDF1- $\alpha$ alone; ' $\mathrm{P}<0.05$ vs. hypoxia + CGS21680 or SDF1- $\alpha+$ CGS21680. RPASMCs, rat pulmonary artery smooth muscle cells; CXCR4, CXC chemokine receptor 4; SDF1- $\alpha$, stromal cell-derived factor-1 $\alpha$; PI, propidium iodide.

40 cycles of denature at $95^{\circ} \mathrm{C}$ for $10 \mathrm{sec}$ and annealing/extension at $60^{\circ} \mathrm{C}$ for $30 \mathrm{sec}$ and the melting curve $\left(95^{\circ} \mathrm{C}\right.$ for $15 \mathrm{sec}$, $60^{\circ} \mathrm{C}$ for $60 \mathrm{sec}$ and $95^{\circ} \mathrm{C}$ for $\left.15 \mathrm{sec}\right) . \beta$-actin was used as an endogenous reference gene to normalize differences in the quantity of total RNA added to each reaction (22). The CXCR4 and $\beta$-actin primer sequences were synthesized by Invitrogen; Thermo Fisher Scientific, Inc., as follows: CXCR4, forward 5'-GGTCTGGAGACTATGACTCCA-3' and reverse 5'-GTG CTGGAACTGGAACACCA-3' (23); $\beta$-actin, forward 5'-GAA CCCTAAGGCCAACC-3' and reverse 5'-TGTCACGCACGA TTTCC-3' (24). The $C_{q}$ values of CXCR4 and $\beta$-actin were recorded as their mRNA levels, respectively. The results were expressed as CXCR4 mRNA levels relative to those of $\beta$-actin as previously described (24).

Cell proliferation assay. The cell proliferation assay kit was purchased from Guangzhou RiboBio Co., Ltd (Guangzhou, China). Following serum starvation with DMEM for $24 \mathrm{~h}$, the RPASMCs $\left(5 \times 10^{5} / \mathrm{ml}\right)$ were cultured in medium containing $10 \mu \mathrm{M}$ Edu at $37^{\circ} \mathrm{C}$, exposed to hypoxia or treated with SDF1- $\alpha$ for $48 \mathrm{~h}$, with or without AMD3100, CGS21680, SCH58261, 8-Br-cAMP or Rp-8-Br-cAMPS. The cell proliferation analysis was then performed according to the manufacturer's protocol.

Statistical analysis. The results are expressed as the mean \pm standard error of the mean. For the comparison of two groups, Student's unpaired t-tests were used. For comparisons of the same group prior to and following treatment, Student's paired t-tests were applied. One-way analysis of variance with the Student-Newman-Keuls test for post-hoc testing of multiple comparisons were performed for the comparison of mean values of more than two groups. $\mathrm{P}<0.05$ (two-tailed) was considered to indicate a statistically significant difference. In all experiments, $\mathrm{n}$ represents the number of replicates in the corresponding experiment.

\section{Results}

Activation of $A_{2 A}$ receptor represses hypoxia- and SDF1- $\alpha$ inducedupregulationof the expression of CXCR4.TheRPASMCs were stained with SMA antibody, DyLight ${ }^{\mathrm{TM}}$ 488-conjugated goat anti-mouse second antibody and PI (Fig. 1A). Images of the immunofluorescence were captured under a confocal microscope and the purity was measured by the ratio of $\alpha$-actin-positive cells to total cells. The results indicated that the purity reached up to $92 \%$, which was suitable for the following experiments (Fig. 1B).

Hypoxia has been reported to increase the expression of CXCR4 in this pathological situation $(16,20,25)$. In order to detect the effects of hypoxia and the activation of $\mathrm{A}_{2 \mathrm{~A}}$ receptor on the protein expression of CXCR4, the RPASMCs were exposed to $3 \% \mathrm{O}_{2}$ for $48 \mathrm{~h}$ with or without the presence of $\mathrm{A}_{2 \mathrm{~A}}$ receptor agonist CGS21680. It was found that hypoxia induced a significant upregulation in the expression of CXCR4, whereas CGS21680 inhibited the increase, which was further reversed by the treatment of $\mathrm{A}_{2 \mathrm{~A}}$ receptor antagonist SCH58261 (Fig. 1C).

It has also been reported that the CXCR4 agonist SDF1- $\alpha$ is able to upregulate the protein expression of CXCR4 in conditions of normoxia $(26,27)$. In the present study, it was also found that SDF1- $\alpha$ significantly increased the protein 
expression of CXCR4 in RPASMCs, which was inhibited by CGS21680 (Fig. 1D). Furthermore, the inhibition of CGS21680 was reversed by SCH58261 (Fig. 1D). In accordance with the results from western blot analysis, it was found that the mRNA levels of CXCR4 were upregulated by hypoxia (Fig. 1E) or SDF1- $\alpha$ (Fig. 1F). In addition, treatment of the cells with or AMD3100 (Fig. 2) also inhibited the expression of CXCR4 induced by SDF1- $\alpha$.

Activation of $A_{2 A}$ receptor inhibits the proliferation of RPASMCs under hypoxia and in the presence of SDF1- $\alpha$. The activation of CXCR4 has been reported to be involved in the proliferation of vascular smooth muscle cells (VSMCs) $(16,20,25-27)$. In the present study, it was also found that hypoxia (Fig. 3) and SDF1- $\alpha$ (Fig. 4) induced significant RPASMC proliferation. As the protein expression of CXCR4 was inhibited by AMD3100 and CGS21680, their effects on the proliferation of RPASMs were further investigated. It was found that the cell proliferation induced by hypoxia (Fig. 3) or SDF1- $\alpha$ (Fig. 4) was inhibited by CGS21680 and/or AMD3100. Furthermore, the inhibition of cell proliferation by CGS21680 was reversed by SCH58261 (Figs. 3 and 4).

Cyclic adenosine monophosphate (cAMP) represses the hypoxia- and SDF1- $\alpha$-induced upregulated expression of CXCR4. As cAMP is the main downstream target and second messenger induced by the activation of $\mathrm{A}_{2 \mathrm{~A}}$ receptor, its effect on the expression of CXCR4 in RPASMCs was investigated in the present study $(28,29)$. It was found that the increased protein expression of CXCR4 was inhibited by the administration of 8-Br-cAMP under hypoxic conditions (Fig. 5A) or SDF1- $\alpha$ treatment (Fig. 5B). The inhibitory effects of 8-Br-cAMP on the protein expression of CXCR4 were reversed by treatment with Rp-8-Br-cAMPS (Fig. 5). The reduction in the protein expression of CXCR4 induced by CGS21680 under hypoxia was also weakened by Rp-8-Br-cAMPS (Fig. 6).

cAMP inhibits the proliferation of RPASMCs under hypoxia and in the presence of SDF1- $\alpha$. As the protein expression of CXCR4 was downregulated by 8-Br-cAMP under hypoxia or treatment with SDF1- $\alpha$, its effect on the proliferation of RPASMs was further examined. It was found that the induction of cell proliferation under hypoxia (Fig. 7) or by SDF1- $\alpha$ (Fig. 8) was inhibited by 8-Br-cAMP. Furthermore, the inhibition of cell proliferation by 8 -Br-cAMP was reversed by Rp-8-Br-cAMPS (Figs. 7 and 8 ). Rp-8-Br-cAMPS also reversed the inhibitory effect of CGS21680 on the proliferation of RPASMs (Fig. 9).

\section{Discussion}

The aberrant proliferation of PASMCs has been well documented as a hallmark pathological feature of all forms of PAH (4), leading to structure remodeling, decreased luminal diameters and ultimately the occlusion of the resistance level of pulmonary arteries $(30,31)$. In the present study, it was demonstrated that hypoxia and SDF1- $\alpha$ independently induced marked proliferation of the RPASMCs in vitro. In addition, the proliferation of RPASMs under hypoxia was partially mediated by activation of the SDF1-CXCR4 axis. Furthermore, the

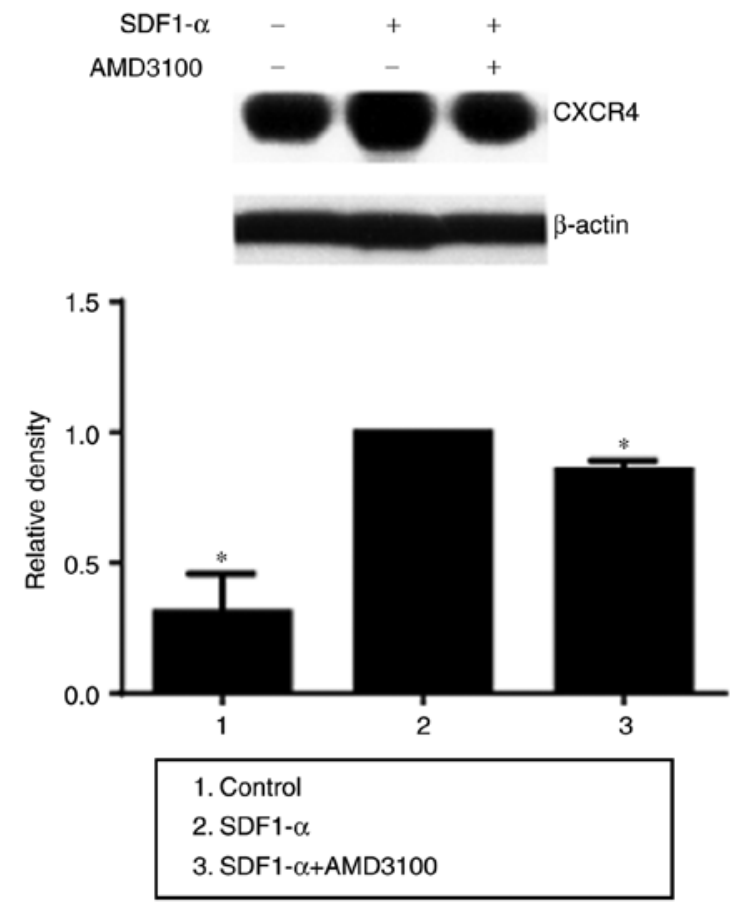

Figure 2. Protein expression of CXCR4 in the presence of SDF1- $\alpha$. The upper panel shows western blots of CXCR4. The lower panel shows summaries of densitometric quantification of the protein expression of CXCR4 normalized by $\beta$-actin levels. SDF1- $\alpha$ was used at a concentration of $100 \mathrm{ng} / \mathrm{ml}$; AMD3100 was used at a concentration of $10 \mu \mathrm{M}$. Data are presented as the mean \pm standard error of the mean ( $\mathrm{n}=4$ for each group). ${ }^{*} \mathrm{P}<0.05$ vs. SDF1- $\alpha$ alone. CXCR4 CXC chemokine receptor 4; SDF1- $\alpha$, stromal cell-derived factor-1 $\alpha$.

activation of $\mathrm{A}_{2 \mathrm{~A}}$ receptor and subsequent elevation in the level of cAMP alleviated the hyperplasia of RPASMCs, possibly by inhibiting the SDF1-CXCR4 signaling pathway.

The molecular basis for the proliferation of PASMCs is complicated, and may involve reduced levels of vasodilators, and increased levels of vasoconstrictors and growth factors $(3,4)$. Among these, activation of the SDF1-CXCR4 axis has been reported as a potential contributor to pulmonary vascular remodeling, possibly by recruiting bone marrow-derived progenitor cells to the pulmonary vasculature, and inducing the proliferation of smooth muscle cells and muscularization of the pulmonary artery (17-20). Consistently, the present study found that the administration of SDF1- $\alpha$ induced a marked increase in the mRNA and protein expression levels of CXCR4 in RPASMCs, and subsequent cell proliferation.

Hypoxia has been reported as a risk factor for the initiation and development of PAH (3). Acute hypoxia normally induces vasoconstriction of the pulmonary vasculature, whereas chronic hypoxia promotes structural remodeling of the pulmonary artery via inducing the proliferation and migration of vascular smooth muscle and the increased deposition of vascular matrix $(32,33)$. In addition, the expression of CXCR4 is predominantly upregulated on VSMCs under several pathological conditions, including high glucose or hypoxia. The increased expression of CXCR4 leads to the aberrant proliferation of VSMCs $(16,20,25,26)$. In the present study, it was also found that hypoxia for $48 \mathrm{~h}$ upregulated the mRNA and protein expression levels of CXCR4 in RPASMCs, possibly by the induction of SDF1- $\alpha$ under pathological conditions $(25,26)$. Furthermore, it has been reported that inhibition of the SDF1-CXCR4 signaling pathway can 
A
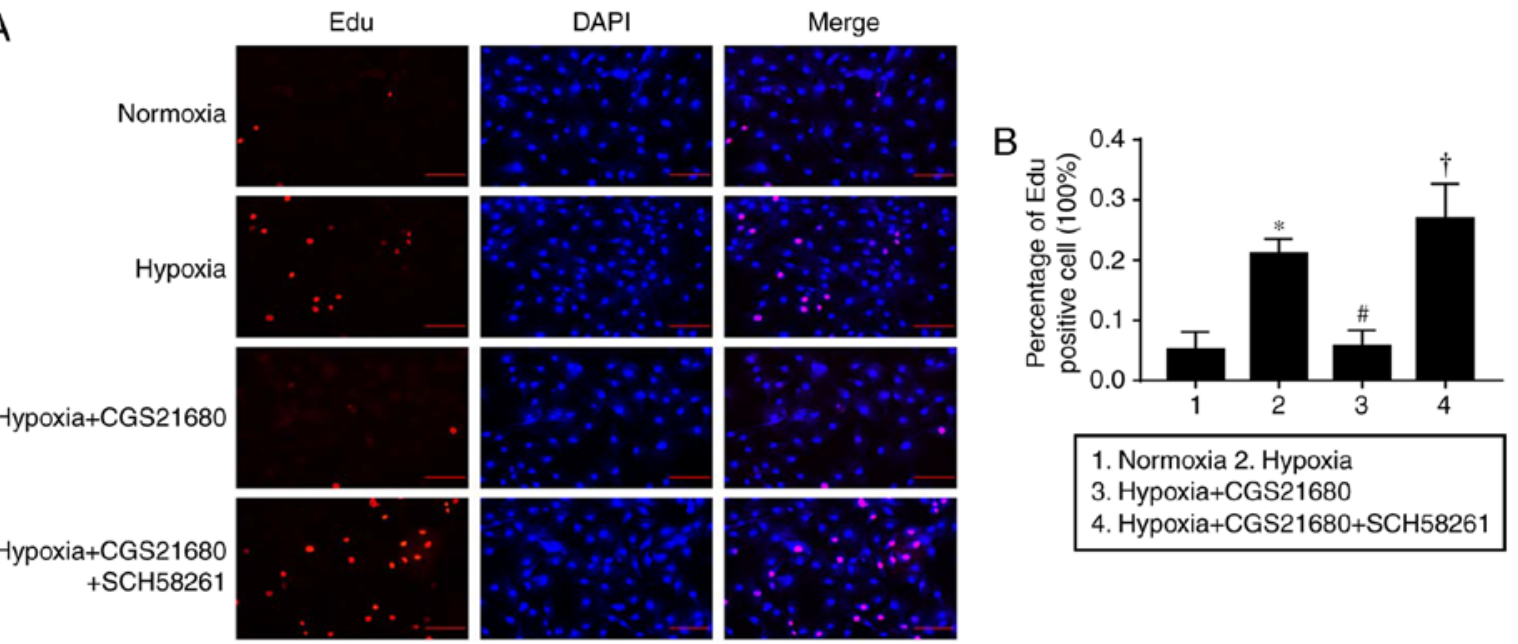

1. Normoxia 2. Hypoxia 3. Hypoxia+CGS21680 4. Hypoxia+CGS21680+SCH58261

Figure 3. Cell proliferation assay measured by immunofluorescence under hypoxia. (A) Immunofluorescence images (scale bar=25 $\mu \mathrm{m}$; magnification, $\mathrm{x} 200$ ). (B) Quantification of Edu-positive cells. Hypoxia, 3\% $\mathrm{O}_{2}$; CGS21680, $2 \mu \mathrm{M}$; SCH58261, $1 \mu \mathrm{M}$. $\mathrm{n}=5$ for each group. "P $<0.05$ vs. normoxia; ${ }^{\text {}} \mathrm{P}<0.05$ vs. hypoxia; ${ }^{\top} \mathrm{P}<0.05$ vs. hypoxia + CGS21680. DAPI, 4',6-diamidino-2-phenylindole dihydrochloride.

A

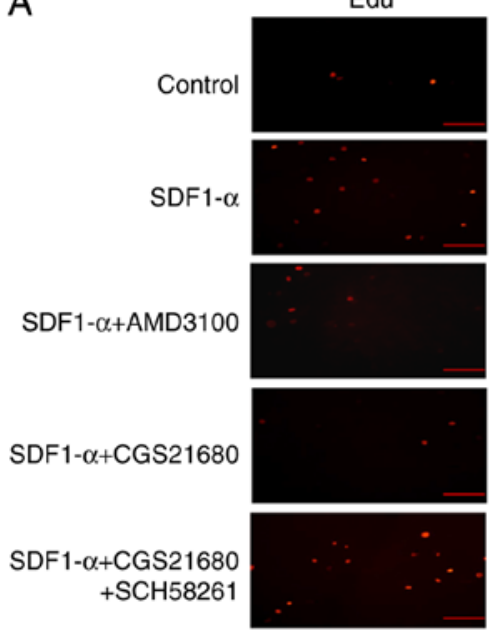

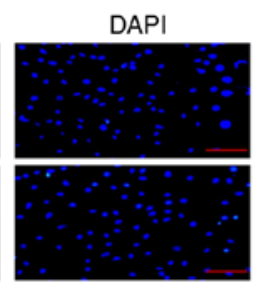
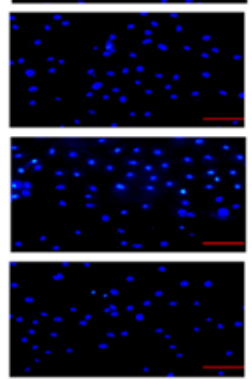
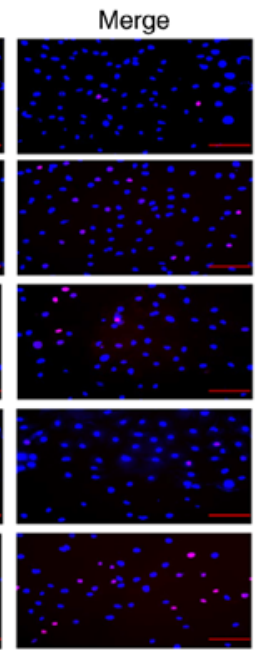

B

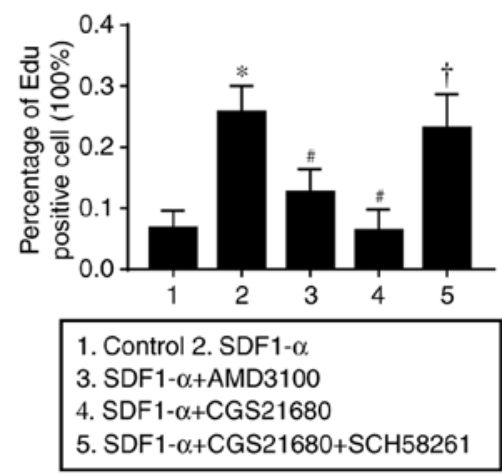

Figure 4. Cell proliferation assay measured by immunofluorescence in the presence of SDF1- $\alpha$. (A) Immunofluorescence images (scale bar=25 $\mu \mathrm{m}$; magnification, x200). (B) Quantification of Edu-positive cells. SDF1- $\alpha, 100 \mathrm{ng} / \mathrm{ml}$; CGS21680, $2 \mu \mathrm{M}$; SCH58261, $1 \mu \mathrm{M}$; AMD3100, $10 \mu \mathrm{M}$. n=5 for each group. ${ }^{*} \mathrm{P}<0.05$ vs. control; ${ }^{\prime} \mathrm{P}<0.05$ vs. SDF1- $\alpha$; ${ }^{\dagger} \mathrm{P}<0.05$ vs. SDF1- $\alpha+$ CGS21680. DAPI, 4',6-diamidino-2-phenylindole dihydrochloride.

suppress PASMC proliferation in hypoxic conditions $(17,19,20)$ In accordance with previous studies, the present study found that the RPASMC proliferation was closely associated with inhibited SDF1-CXCR4 signaling under hypoxia.

It has been reported that the $\mathrm{A}_{2 \mathrm{~A}}$ receptor is expressed on PASMCs and mediates the vasodilatory effects of adenosine on the pulmonary vasculature (9). In addition, the absence of adenosine signaling in $A_{2 A}$ receptor-knockout mice has been reported to be closely associated with the development of PAH, characterized by abnormal sclerosis/stenosis of distal pulmonary arteries due to increased smooth muscle proliferation and collagen deposition. By contrast, pharmacological activation of the $\mathrm{A}_{2 \mathrm{~A}}$ receptor can partially reverse these pathological changes (11-14). However, the detailed mechanisms that mediate the beneficial effects of adenosine signaling remain to be fully elucidated. The activation of the $\mathrm{A}_{2 \mathrm{~A}}$ receptor may downregulate the expression of CXCR4 in $\mathrm{CD} 4{ }^{+} \mathrm{T}$-cells, indicating that a possible association between
$\mathrm{A}_{2 \mathrm{~A}}$ receptor activation and the expression of CXCR4 may also exist in the pulmonary vasculature (21). The hypoxia- and SDF1- $\alpha$-induced upregulation of CXCR4 and corresponding cell proliferation in the RPASMCs were inhibited by administration of the $\mathrm{A}_{2 \mathrm{~A}}$ receptor agonist CGS21680.

The vasodilatory effects of adenosine have been reported to be mediated by its binding to corresponding adenosine A receptors and the subsequent activation of downstream signaling pathways, including the cAMP-dependent or -independent pathways $(28,29,34,35)$. Accordingly, cAMP may be also involved in alleviating SDF1-CXCR4-associated RPASMC proliferation. In the present study, the administration of cAMP analogue 8-Br-cAMP downregulated the protein expression of CXCR4 and inhibited the proliferation of RPASMCs induced by hypoxia and SDF1- $\alpha$. The effect of CGS21680 was inhibited by the cAMP antagonist $\mathrm{Rp}-8$-Br-cAMPS, revealing that the alleviating effect of $\mathrm{A}_{2 \mathrm{~A}}$ receptor activation was mainly mediated by the increased 
A
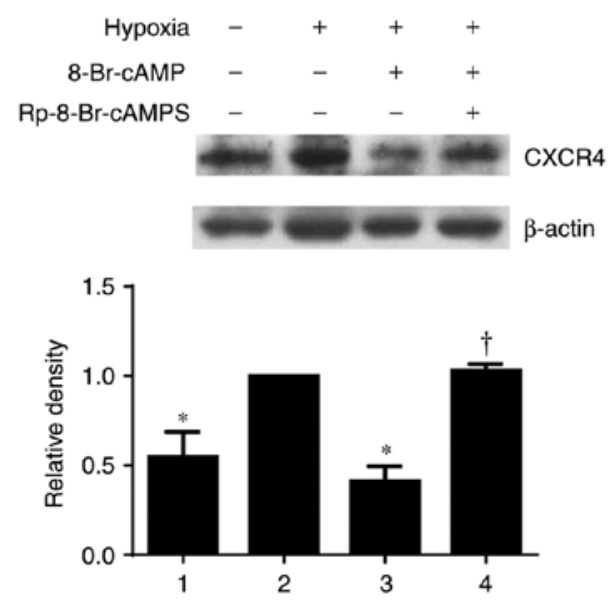

1. Normoxia 2. Hypoxia

3. Hypoxia+8-Br-cAMP

4. Hypoxia+8-Br-cAMP+Rp-8-Br-cAMPS
B
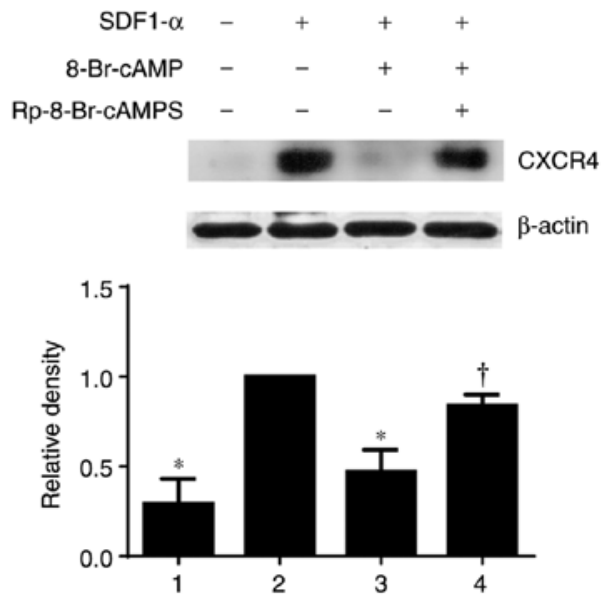

1. Control 2. SDF1- $\alpha$

3. SDF1- $\alpha+8-B r-C A M P$

4. SDF1- $\alpha+8-B r-C A M P+R p-8-B r-c A M P S$

Figure 5. Protein expression of CXCR4 under (A) hypoxia or (B) in the presence of SDF1- $\alpha$. The upper panels show western blots of CXCR4. The lower panels show summaries of densitometric quantification of the protein expression of CXCR4 normalized by $\beta$-actin levels. Hypoxia, $3 \%$ O ${ }_{2}$, SDF1- $\alpha, 100$ ng/ml; 8-Br-cAMP, $30 \mu \mathrm{M}$; Rp-8-Br-cAMPS, $30 \mu \mathrm{M}$. Data are presented as the mean \pm standard error of the mean ( $\mathrm{n}=4-5$ for each group). ${ }^{*}<0.05$ vs. hypoxia or SDF1- $\alpha$ alone; ${ }^{\dagger} \mathrm{P}<0.05$ vs. hypoxia + 8-Br-cAMP or SDF1- $\alpha+8$-Br-cAMP. CXCR4, CXC chemokine receptor 4; SDF1- $\alpha$, stromal cell-derived factor 1 $\alpha$; Rp-8-Br-cAMP; 8-bromoadenosine 3',5'-cyclic monophosphate sodium salt; Rp-8-Br-cAMPS, 8-bromoadenosine-3',5'-cyclic monophosphorothioate.

$\begin{array}{rcccc}\text { Hypoxia } & - & + & + & + \\ \text { CGS21680 } & - & - & + & + \\ \text { Rp-8-Br-cAMPS } & - & - & - & +\end{array}$
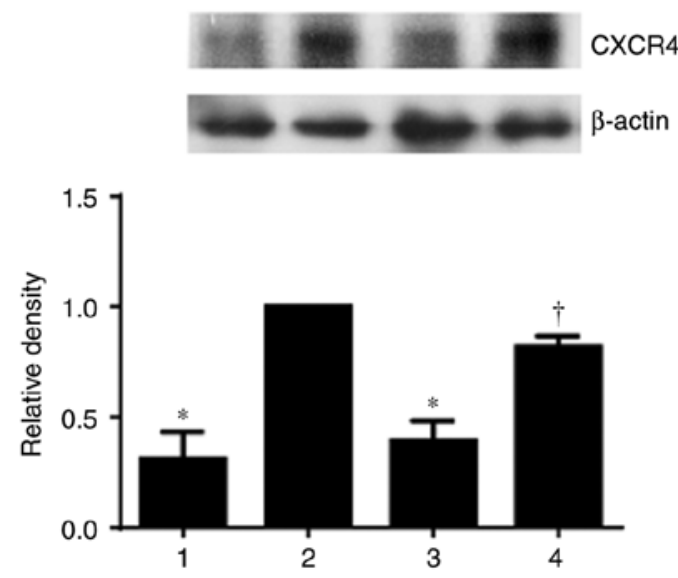

1. Normoxia 2. Hypoxia

3. Hypoxia+CGS21680

4. Hypoxia+CGS21680+Rp-8-Br-cAMPS

Figure 6. Protein expression of CXCR4 under hypoxia. The upper panel shows western blots of CXCR4. The lower panel shows summaries of densitometric quantification of protein expression of CXCR4 normalized by $\beta$-actin levels. Hypoxia, 3\% $\mathrm{O}_{2}$; CGS21680, $2 \mu \mathrm{M}$; Rp-8-Br-cAMPS, $30 \mu \mathrm{M}$ Data are presented as the mean \pm standard error of the mean $(n=3$ for each group). ${ }^{*} \mathrm{P}<0.05$ vs. hypoxia alone; ${ }^{\dagger} \mathrm{P}<0.05$ vs. hypoxia + CGS21680 $(\mathrm{P}<0.05)$ CXCR4, CXC chemokine receptor 4; SDF1- $\alpha$, stromal cell-derived factor $1 \alpha$ Rp-8-Br-cAMP; 8-bromoadenosine 3',5'-cyclic monophosphate sodium salt; Rp-8-Br-cAMPS, 8-bromoadenosine-3',5'-cyclic monophosphorothioate.

level of cAMP in the RPASMCs. Taken together, these results indicated that the downregulated expression of CXCR4 on RPASMCs under hypoxia or stimulation by SDF1- $\alpha$ may be mediated by activation of the $\mathrm{A}_{2 \mathrm{~A}}$ receptor-cAMP signaling pathway.

In the present study, it was shown that activation of the SDF1-CXCR4 signaling pathway may contribute to the proliferation of RPASMCs under hypoxic conditions. By contrast, activation of the $A_{2 A}$ receptor and the subsequent increase in the level of cAMP reversed hypoxia-induced RPASMC proliferation by inhibiting SDF1-CXCR4 signaling. Taken together, these results indicated that the reduced SDF1-CXCR4 signaling mediated by $\mathrm{A}_{2 \mathrm{~A}}$ receptor activation may be of therapeutic benefit in the treatment of PAH.

\section{Acknowledgements}

Not applicable.

\section{Funding}

This study was supported in part by the National Natural Science Foundation of China, (grant nos. 81270110 and 81470250).

\section{Availability of data and materials}

The datasets used and/or analyzed during the current study are available from the corresponding author on reasonable request.

\section{Authors' contributions}

YW, LY and LW conceived and designed the research. YW, LY, KJ, YN, SH, XW, RQ and XL performed the experiments. YW, LY, KJ and YN analyzed the data. All authors interpreted the results of the experiments. YW, LY and LW prepared the figures. YW, LY and LW drafted the manuscript. All authors edited and revised the manuscript and approved the final version to be published. 
A
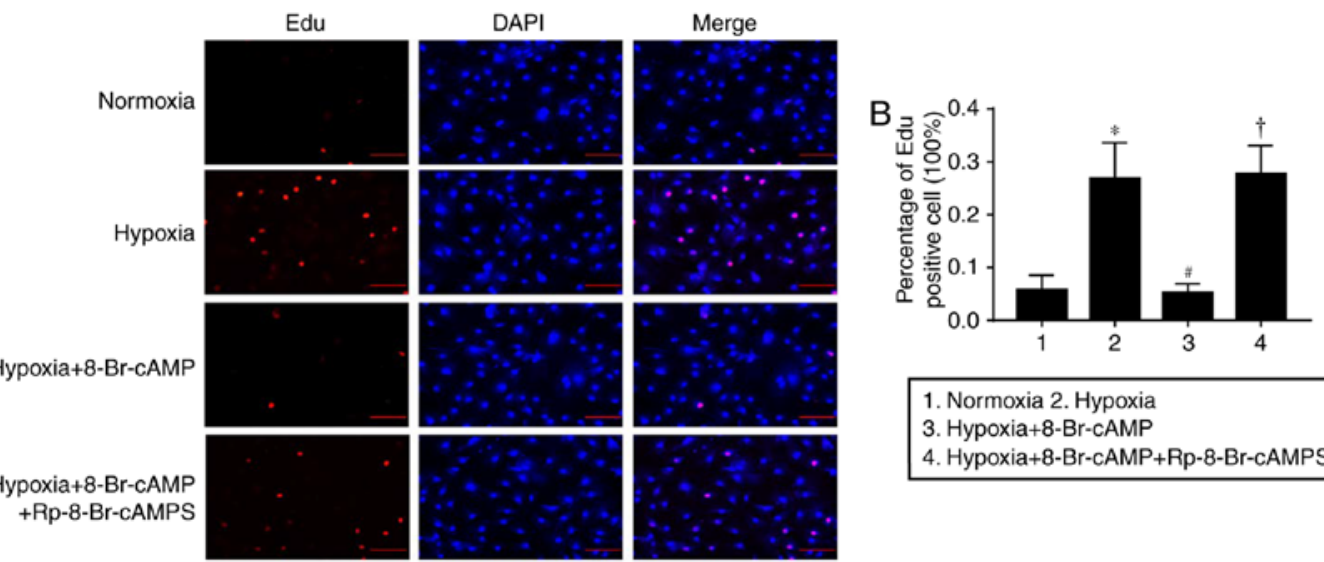

1. Normoxia 2. Hypoxia

3. Hypoxia+8-Br-cAMP

4. Hypoxia+8-Br-cAMP+Rp-8-Br-cAMPS

Figure 7. Cell proliferation assay measured by immunofluorescence under hypoxia. (A) Immunofluorescence images (scale bar $=25 \mu \mathrm{m}$; magnification, x200). (B) Quantification of Edu-positive cells. Hypoxia, 3\% $\mathrm{O}_{2} ; 8$-Br-cAMP, $30 \mu \mathrm{M}$; Rp-8-Br-cAMPS, $30 \mu \mathrm{M}$ ( $\mathrm{n}=4$ for each group). "P<0.05 vs. normoxia; ${ }^{\#} \mathrm{P}<0.05$ vs. hypoxia; ${ }^{\dagger} \mathrm{P}<0.05$ vs. hypoxia + 8-Br-cAMP. Rp-8-Br-cAMP; 8-bromoadenosine 3',5'-cyclic monophosphate sodium salt; Rp-8-Br-cAMPS, 8-bromoadenosine-3',5'-cyclic monophosphorothioate; DAPI, 4',6-diamidino-2-phenylindole dihydrochloride.

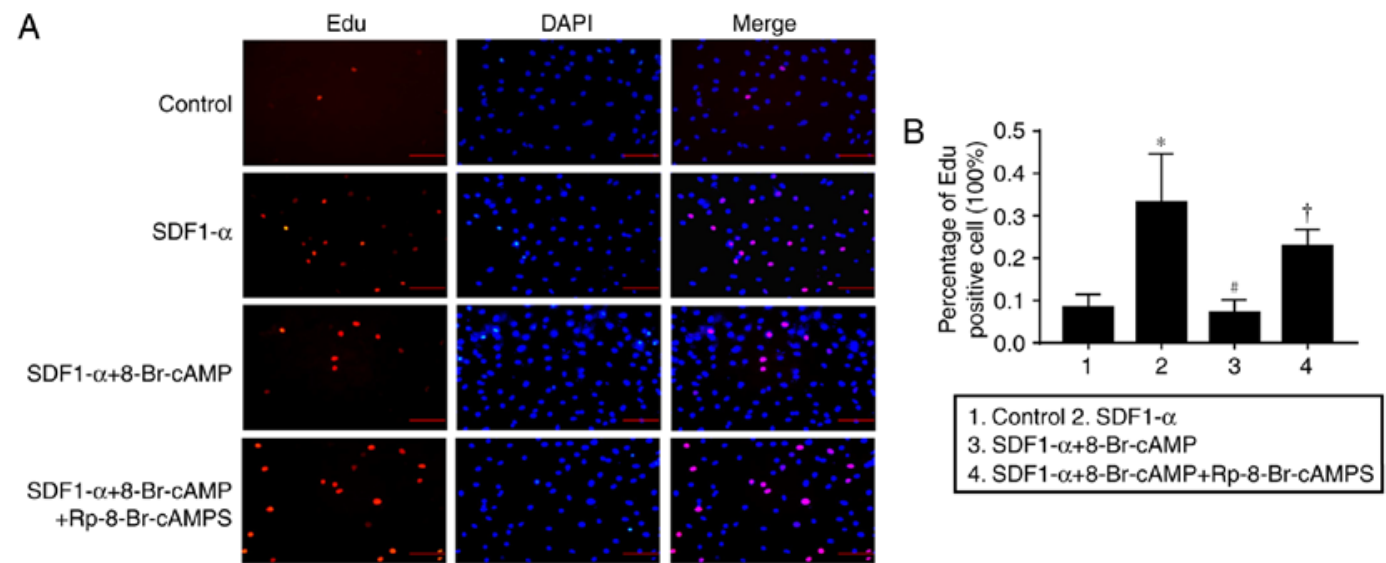

Figure 8. Cell proliferation assay measured by immunofluorescence in the presence of SDF1- $\alpha$. (A) Immunofluorescence images (scale bar $=25 \mu \mathrm{m}$; magnification, x200). (B) Quantification of Edu-positive cells. SDF1- $\alpha, 100 \mathrm{ng} / \mathrm{ml}$; 8-Br-cAMP, $30 \mu \mathrm{M}$; Rp-8-Br-cAMPS, $30 \mu \mathrm{M}$ (n=5 for each group). ${ }^{*} \mathrm{P}<0.05$ vs. control; ${ }^{*} \mathrm{P}<0.05$ vs. SDF1- $\alpha$; ${ }^{\mathrm{P}}<0.05$ vs. SDF1- $\alpha+8$-Br-cAMP $(\mathrm{P}<0.05)$. CXCR4, CXC chemokine receptor 4; SDF1- $\alpha$, stromal cell-derived factor-1 $\alpha$; Rp-8-Br-cAMP; 8-bromoadenosine 3',5'-cyclic monophosphate sodium salt; Rp-8-Br-cAMPS, 8-bromoadenosine-3',5'-cyclic monophosphorothioate; DAPI, 4',6-diamidino-2-phenylindole dihydrochloride.

A
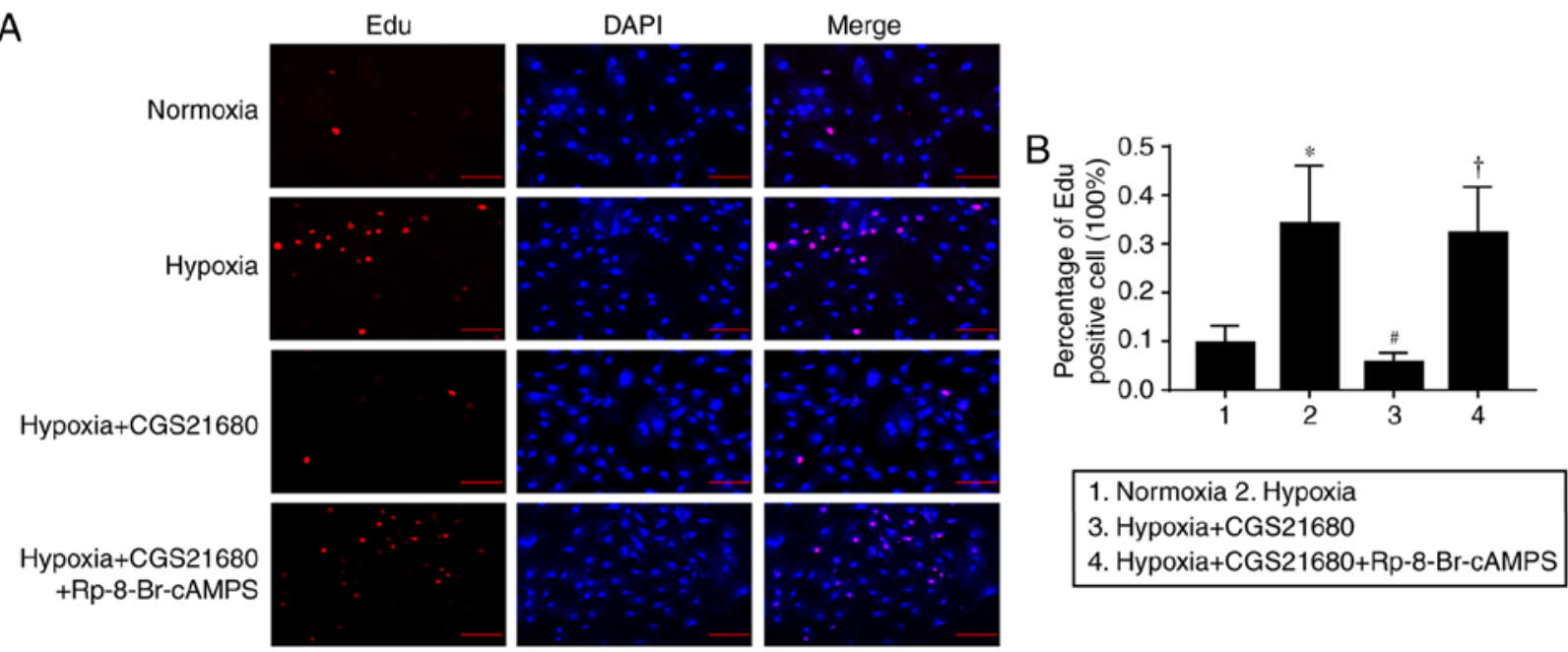

Figure 9. Cell proliferation assay measured by immunofluorescence under hypoxia. (A) Immunofluorescence images (scale bar=25 $\mu \mathrm{m}$; magnification, x200). (B) Quantification of Edu-positive cells. Hypoxia, 3\% $\mathrm{O}_{2}$; CGS21680, $2 \mu \mathrm{M}$; Rp-8-Br-cAMPS, $30 \mu \mathrm{M}$ (n=4 for each group). "P $<0.05 \mathrm{vs}$. normoxia; ${ }^{\#} \mathrm{P}<0.05$ vs. hypoxia; ${ }^{\top} \mathrm{P}<0.05$ vs. cells treated with hypoxia + CGS21680. Rp-8-Br-cAMPS, 8-bromoadenosine-3',5'-cyclic monophosphorothioate; DAPI, 4',6-diamidino-2-phenylindole dihydrochloride. 


\section{Ethics approval and consent to participate}

The present study was approved by the guidelines of Wenzhou Medical College (ethics approval no. wydw2015-0201) and the National Institutes of Health Standards of Animal Care.

\section{Consent for publication}

Not applicable.

\section{Competing interests}

The authors declare that they have no competing interests.

\section{References}

1. Dorfmüller P, Humbert M, Capron F and Müller KM: Pathology and aspects of pathogenesis in pulmonary arterial hypertension. Sarcoidosis Vasc Diffuse Lung Dis 20: 9-19, 2003.

2. Barst RJ, McGoon M, Torbicki A, Sitbon O, Krowka MJ, Olschewski $\mathrm{H}$ and Gaine S: Diagnosis and differential assessment of pulmonary arterial hypertension. J Am Coll Cardiol 43 (Suppl 12): 40S-47S, 2004.

3. Farber HW and Loscalzo J: Pulmonary arterial hypertension. NEngl J Med 351: 1655-1665, 2004.

4. Schermuly RT, Ghofrani HA, Wilkins MR and Grimminger F: Mechanisms of disease: Pulmonary arterial hypertension. Nat Rev Cardiol 8: 443-455, 2011.

5. Guignabert C, Tu L, Le Hiress M, Ricard N, Sattler C, Seferian A, Huertas A, Humbert M and Montani D: Pathogenesis of pulmonary arterial hypertension: Lessons from cancer. Eur Respir Rev 22: 543-551, 2013.

6. Saadjian AY, Paganelli F, Gaubert ML, Levy S and Guieu RP: Adenosine plasma concentration in pulmonary hypertension. Cardiovasc Res 43: 228-236, 1999.

7. Konduri GG, Woodard LL, Mukhopadhyay A and Deshmukh DR: Adenosine is a pulmonary vasodilator in newborn lambs. Am Rev Respir Dis 146: 670-676, 1992.

8. Pearl RG: Adenosine produces pulmonary vasodilation in the perfused rabbit lung via an adenosine A2 receptor. Anesth Analg 79: 46-51, 1994.

9. McCormack DG, Clarke B and Barnes PJ: Characterization of adenosine receptors in human pulmonary arteries. Am J Physiol 256: H41-H46, 1989.

10. Alencar AK, Pereira SL, Montagnoli TL, Maia RC, Kümmerle AE, Landgraf SS, Caruso-Neves C, Ferraz EB Tesch R, Nascimento JH, et al: Beneficial effects of a novel agonist of the adenosine $\mathrm{A}_{2 \mathrm{~A}}$ receptor on monocrotaline-induced pulmonary hypertension in rats. Br J Pharmacol 169: 953-962, 2013.

11. Xu MH, Gong YS, Su MS, Dai ZY, Dai SS, Bao SZ, Li N, Zheng RY, He JC, Chen JF and Wang XT: Absence of the adenosine $A_{2 A}$ receptor confers pulmonary arterial hypertension and increased pulmonary vascular remodeling in mice. $\mathrm{J}$ Vasc Res 48: 171-183, 2011.

12. Shang P, He ZY, Chen JF, Huang SY, Liu BH, Liu HX and Wang XT: Absence of the adenosine $\mathrm{A}_{2 \mathrm{~A}}$ receptor confers pulmonary arterial hypertension through RhoA/ROCK signaling pathway in mice. J Cardiovasc Pharmacol 66: 569-575, 2015.

13. Alencar AK, Pereira SL, da Silva FE, Mendes LV, Cunha Vdo M, Lima LM, Montagnoli TL, Caruso-Neves C, Ferraz EB, Tesch R, et al: N-acylhydrazone derivative ameliorates monocrotaline-induced pulmonary hypertension through the modulation of adenosine AA2R activity. Int J Cardiol 173: 154-162, 2014.

14. Huang X, Zou L, Yu X, Chen M, Guo R, Cai H, Yao D, $\mathrm{Xu} \mathrm{X}$, Chen Y, Ding C, et al: Salidroside attenuates chronic hypoxia-induced pulmonary hypertension via adenosine $\mathrm{A}_{2 \mathrm{~A}}$ receptor related mitochondria-dependent apoptosis pathway. J Mol Cell Cardiol 82: 153-166, 2015.

15. Zernecke A, Schober A, Bot I, von Hundelshausen P, Liehn EA, Möpps B, Mericskay M, Gierschik P, Biessen EA and Weber C: SDF-1alpha/CXCR4 axis is instrumental in neointimal hyperplasia and recruitment of smooth muscle progenitor cells. Circ Res 96: 784-791, 2005.
16. Schober A: Chemokines in vascular dysfunction and remodeling. Arterioscler Thromb Vasc Biol 28: 1950-1959, 2008.

17. Young KC, Torres E, Hatzistergos KE, Hehre D, Suguihara C and Hare JM: Inhibition of the SDF-1/CXCR4 axis attenuates neonatal hypoxia-induced pulmonary hypertension. Circ Res 104: 1293-1301, 2009.

18. Yu L and Hales CA: Effect of chemokine receptor CXCR4 on hypoxia-induced pulmonary hypertension and vascular remodeling in rats. Respir Res 12: 21, 2011.

19. Farkas D, Kraskauskas D, Drake JI, Alhussaini AA, Kraskauskiene V, Bogaard HJ, Cool CD, Voelkel NF and Farkas L: CXCR4 inhibition ameliorates severe obliterative pulmonary hypertension and accumulation of $\mathrm{C}-\mathrm{kit}^{+}$cells in rats. PLoS One 9: e89810, 2014.

20. Wei L, Zhang B, Cao W, Xing H, Yu X and Zhu D: Inhibition of CXCL12/CXCR4 suppresses pulmonary arterial smooth muscle cell proliferation and cell cycle progression via PI3K/Akt pathway under hypoxia. J Recept Signal Transduct Res 35: 329-339, 2015.

21. By Y, Durand-Gorde JM, Condo J, Lejeune PJ, Fenouillet E, Guieu R and Ruf J: Monoclonal antibody-assisted stimulation of adenosine $A_{2 A}$ receptors induces simultaneous downregulation of CXCR4 and CCR5 on CD4 ${ }^{+}$T-cells. Hum Immunol 71: 1073-1076, 2010.

22. Nolan T, Hands RE and Bustin SA: Quantification of mRNA using real-time RT-PCR. Nat Protoc 1: 1559-1582, 2006.

23. Ji JF, He BP, Dheen ST and Tay SS: Expression of chemokine receptors CXCR4, CCR2, CCR5 and CX3CR1 in neural progenitor cells isolated from the subventricular zone of the adult rat brain. Neurosci Lett 355: 236-240, 2004.

24. Wang Y, Deng Y and Zhou GQ: SDF-1alpha/CXCR4-mediated migration of systemically transplanted bone marrow stromal cells towards ischemic brain lesion in a rat model. Brain Res 1195: 104-112, 2008.

25. Dahal BK, Heuchel R, Pullamsetti SS, Wilhelm J, Ghofrani HA, Weissmann N, Seeger W, Grimminger F and Schermuly RT: Hypoxic pulmonary hypertension in mice with constitutively active platelet-derived growth factor receptor- $\beta$. Pulm Circ 1: 259-268, 2011.

26. Jie W, Wang X, Zhang Y, Guo J, Kuang D, Zhu P, Wang G and Ao Q: SDF-1 $\alpha /$ CXCR4 axis is involved in glucose-potentiated proliferation and chemotaxis in rat vascular smooth muscle cells. Int J Exp Pathol 91: 436-444, 2010.

27. Pan $\mathrm{CH}$, Chen $\mathrm{CW}$, Sheu MJ and $\mathrm{Wu} \mathrm{CH}$ : Salvianolic acid B inhibits SDF-1 $\alpha$-stimulated cell proliferation and migration of vascular smooth muscle cells by suppressing CXCR4 receptor. Vascul Pharmacol 56: 98-105, 2012.

28. Hong KW, Shin HK, Kim HH, Choi JM, Rhim BY and Lee WS: Metabolism of cAMP to adenosine: Role in vasodilation of rat pial artery in response to hypotension. Am J Physiol 276: H376-H382, 1999.

29. Carroll MA, Doumad AB, Li J, Cheng MK, Falck JR and McGiff JC: Adenosine 2A receptor vasodilation of rat preglomerular microvessels is mediated by EETs that activate the cAMP/PKA pathway. Am J Physiol Renal Physiol 291: F155-F161, 2006.

30. Humbert M, Morrell NW, Archer SL, Stenmark KR, MacLean MR, Lang IM, Christman BW, Weir EK, Eickelberg O, Voelkel NF and Rabinovitch M: Cellular and molecular pathobiology of pulmonary arterial hypertension. J Am Coll Cardiol 43 (Suppl 12): 13S-24S, 2004.

31. Morrell NW, Adnot S, Archer SL, Dupuis J, Jones PL, MacLean MR, McMurtry IF, Stenmark KR, Thistlethwaite PA, Weissmann N, et al: Cellular and molecular basis of pulmonary arterial hypertension. J Am Coll Cardiol 54 (Suppl 1): S20-S31, 2009.

32. Stenmark KR, Fagan KA and Frid MG: Hypoxia-induced pulmonary vascular remodeling: Cellular and molecular mechanisms. Circ Res 99: 675-691, 2006.

33. Kato M and Staub NC: Response of small pulmonary arteries to unilobar hypoxia and hypercapnia. Circ Res 19: 426-440, 1966.

34. Hein TW and Kuo L: cAMP-independent dilation of coronary arterioles to adenosine: Role of nitric oxide, $G$ proteins, and K(ATP) channels. Circ Res 85: 634-642, 1999.

35. Murphy K, Gerzanich V, Zhou H, Ivanova S, Dong Y, Hoffman G, West GA, Winn HR and Simard JM: Adenosine- $\mathrm{A}_{2 \mathrm{~A}}$ receptor down-regulates cerebral smooth muscle L-type $\mathrm{Ca} 2+$ channel activity via protein tyrosine phosphatase, not cAMP-dependent protein kinase. Mol Pharmacol 64: 640-649, 2003. 